\title{
A FICCIONALIZAÇÃO DA MEMÓRIA E O TRAUMA NA COMPOSIÇÃO DO ROMANCE PONCIÁ VIVÊNCIO, DE CONCEIÇÃO EVARISTO
}

\author{
SOUSA, Ângela Cristina Fróes de ${ }^{1}$
}

\begin{abstract}
RESUMO: Este artigo analisa as representações mnemônicas e o seu entrelaçamento com as experiências traumáticas que compõem as lembranças dos personagens no romance Ponciá Vicêncio (2003). Assim, busca-se evidenciar como a escritora Conceição Evaristo utiliza tais elementos como fio condutor do texto, visando compor uma narrativa insurgente que denuncia as heranças traumáticas relacionadas ao processo de escravidão, bem como evidencia a rememoração da história dos afrodescendentes, denunciando a invisibilidade do sujeito negro, sobretudo, o feminino, por meio da análise no silêncio da protagonista Ponciá, com profundas reflexões sobre a condição social, à medida que vai restituindo humanidades negadas e silenciadas após séculos de racismo estrutural.
\end{abstract}

PALAVRAS-CHAVE: literatura; memória; trauma; silêncio.

\section{LA FICTIONNALISATION DE LA MÉMOIRE ET DU TRAUMA DANS LA COMPOSITION DE LA ROMANCE PONCIÁ VIVENNCIO, D'EVARISTO CONCEPTION}

RÉSUMÉ : Cet article analyse les représentations mnémoniques et leur entrelacement avec les expériences traumatisantes qui composent la mémoire des personnages du roman Ponciá Vicêncio (2003). Ainsi, il cherche à montrer comment l'écrivain Conceição Evaristo utilise ces éléments comme fil conducteur du texte, visant à composer un récit insurgé qui dénonce les héritages traumatisants liés au processus d'esclavage, ainsi que la preuve du souvenir de l'histoire des Afro-descendants, dénonçant l'invisibilité du sujet noir, notamment le féminin, à travers l'analyse dans le silence du protagoniste Ponciá, avec des réflexions profondes sur la

${ }^{1}$ Mestranda em Estudos Literários pela Universidade Federal de Viçosa, angela.pitagoras@ outlook.com Jangada | nr. 14, jul/dez, 2019 | ISSN 2317-4722 
condition sociale, car elle restaure des humanités niées et réduites au silence après des siècles de racisme structurel.

MOTS-CLÉS : littérature ; Mémoire ; traumatisme ; silence.

\section{INTRODUÇÃO}

$\mathrm{Na}$ cena literária, as novas perspectivas de narrativas que começam a desencadear com mais intensidade têm como mote a questão da memória e o modo como os autores propõem, em suas escrituras, a profunda relação entre a memória e o passado traumático, aliados a um possível dialogismo com projetos identitários que tratam das vítimas e seus descendentes. Consoante Seligmann-Silva (2001), "a arte da memória, assim como a literatura de testemunho, é uma arte da leitura de cicatrizes", que expõe por meio de uma memória coletiva a experiência traumática gerada pela violência de um sistema social vigente.

Nessa lógica, é obra exemplar É isto um homem? do escritor italiano Primo Levi, que tematiza através da memória traumática as experiências provenientes de sua detenção no campo de concentração de Auschwitz, em 1944. Já no prefácio o autor destaca que a "a história dos campos de extermínio deveria ser compreendida por todos como sinistro sinal de perigo", acrescentando que "a necessidade de contar "aos outros", de tornar "os outros" participantes, alcançou entre nós, antes e depois da libertação, caráter de impulso imediato e violento, até o ponto de competir com outras necessidades elementares." Levando-se em conta a tarefa árdua e ambígua de rememorar a catástrofe como a ferida aberta do trauma, o filósofo Theodor W. Adorno lança em 1949, no texto Crítica, cultura e sociedade, o questionamento sobre a possibilidade de fazer poesia após a barbárie de Auschwitz.

Decerto, tal indagação é totalmente compreensível após a publicação da obra Dialética negativa (1967), um debate à visão totalitária de mundo, depois dos cenários de brutalidade moral oriundos de Auschwitz, razão pela qual o professor de teoria literária, Seligmann-Silva (2009), assevera que o testemunho é analisado como parte de uma complexa "política da memória". Assim, para o autor, "a humanidade deve orientar seu pensamento e ação de tal modo que Auschwitz não se repita, que nada semelhante ocorra." (SELIGMANN-SILVA, 2009, p. 88). Nessa perspectiva, após o término do regime nazista e das atrocidades cometidas e registradas em detalhes, o questionamento de Adorno é totalmente coerente e estende-se não 
somente às questões de cunho artístico, como também à própria existência do ser e suas relações nas esferas sociais.

A propósito, a questão da shoah na Alemanha foi desencadeadora das discussões sobre os limites existentes entre ficção, história e memória, precisamente pelo trauma gerado em virtude desse evento. Relacionando a questão do testemunho e da memória, Seligmann-Silva (2001) pontua que ao pensarmos Auschwitz é compreensível que a questão central não esteja pautada em uma existência ou não da "realidade", mas principalmente em nossa capacidade de percebê-la e simbolizá-la. Nesse sentido, o entrelaçamento da ficção à história não enfraquece o processo de representação desta última, mas contribui para realizá-lo, como podemos perceber em Paul Ricoeur (2010, p. 322):

A ficção dá ao narrador horrorizado olhos. Olhos para ver e chorar. O estado atual da literatura do holocausto comprova-o amplamente. Ou a contagem dos cadáveres ou a legenda das vítimas. Entre ambas, intercala-se uma explicação histórica, difícil (se não impossível) de escrever [...]

Nessa ótica, a ficcionalização da memória e o trauma são temáticas cada vez mais discutidas e evidenciadas nas artes. Ao pensar essas questões, o escritor Andreas Huyssen (2000, p. 10) assevera que,

Discursos de memória de um novo tipo emergiram pela primeira vez no ocidente depois da década de 1960, no rastro da descolonização e dos novos movimentos sociais em sua busca por histórias alternativas e revisionistas.

Assim, para Seligmann-Silva (2001) a leitura estética do passado torna-se necessária, pois evita o processo de "musealização" do ocorrido, tendo em vista que esta modalidade busca relacionar tal fato ativo no presente, com o objetivo de explorar o passado, suas ruínas, barbáries e cicatrizes.

Um exemplo dessas buscas por histórias revisionistas é evidenciado na análise das performances Yuyachkani - um grupo de teatro do Peru - e desenvolvido por Diana Taylor em seus estudos sobre a memória cultural nas Américas. Tendo em vista que as performances do Yuyachkani tornam visível a história de um trauma cumulativo, referente à violência contra os povos indígenas, em que a violência passada se mistura à crise atual. Para Taylor (2013), a 


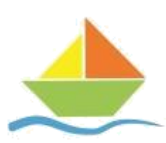

performance oferece as "trilhas da memória" que possibilitam ao povo representar as lutas antigas de poder e reconhecimento que permanecem no Peru contemporâneo.

Em contraste, Andreas Huyssen, em Seduzidos pela memória: arquitetura, monumentos e mídia (2000), analisa as questões crucias da cultura contemporânea, que estão localizadas entre o limiar da memória dramática e de seu processo de globalização. Segundo Huyssen, vivemos a era de mercadorização da memória, na qual a obsessão pública pela memória chocase com a possibilidade do esquecimento em virtude dos inúmeros recursos midiáticos. Assim, o crítico argumenta que sobrevivemos na era dos "passados presentes" em relação aos "futuros presentes", pois muitas memórias produzidas pela indústria cultural têm como objetivo a comercialização, deturpando ou até mesmo não envolvendo os acontecimentos com seu verdadeiro sentido, produzindo uma espécie de realidade equivocada que povoa o imaginário coletivo.

Nesta perspectiva, em que a memória é extensamente explorada, o projeto literário da escritora Conceição Evaristo vislumbra uma produção memorialística, que denuncia as supostas interpretações das sombras extensas do passado, por meio de uma poética de alteridade marcada pela ênfase na memória e no trauma, que aparecem frequentemente como relevo na sua escrita ao conceber profundas reflexões em torno da memória individual e coletiva de suas personagens, tal como ocorre nas reminiscências tecidas pela protagonista do romance Ponciá Vicêncio (2003), através de uma narrativa que apresenta a memória de modo fragmentário, dialogando ora com a memória coletiva que denuncia o passado de escravidão, ora com a memória individual que visa a construir sua própria identidade.

Portanto, as tessituras de Conceição Evaristo se configuram como repositório da memória diaspórica e têm como eixo evidenciar as experiências traumáticas que refletem a violência do presente vinculada ao passado, por meio do resgate da ancestralidade, através da qual, o drama das populações negras, não apenas se representa, mas acontece de modo ativo.

\section{ESCREVIVÊNCIAS: ESCRITA E MEMÓRIA COMO CERNE DO ATO DE NARRAR}

As obras de Conceição Evaristo se caracterizam pela ênfase na história, na memória e nas experiências traumáticas, por meio de uma escrita marcada pelo termo escrevivências, neologismo que explora a ideia de escrever, viver e ser. Bem como expressa o compromisso com o caráter identitário, documental e coletivo por meio de um fazer poético, voltado para a Jangada | nr. 14, jul/dez, 2019 | ISSN 2317-4722 


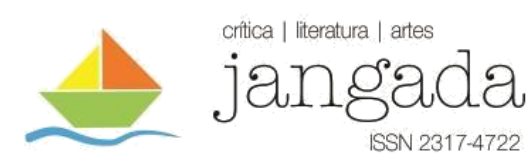

ressignificação da identidade negra, através de uma produção marcada por reflexões, sobretudo, de sujeitos femininos negros que têm urgência em reafirmar as identidades afrodescendentes e denunciar principalmente a herança decorrente do processo de escravidão. Nas palavras da escritora, "a nossa escrevivência não pode ser lida como histórias para 'ninar os da casa grande' e sim para incomodá-los em seus sonos injustos" (2005).

Esse complexo temático tratado pela autora é evidenciado por Achille Mbembe (2018) no ensaio intitulado Necropolítica, no qual discute as experiências contemporâneas de destruição humana, tal como ocorreu nos campos de extermínio e o processo de escravidão, sugerindo a possibilidade de desenvolver uma leitura da política, da soberania e do sujeito, diferente daquela que herdamos do discurso filosófico da modernidade. Para Mbembe (2018), qualquer relato histórico que trate do surgimento do terror moderno precisa tratar da escravidão, que pode ser considerada uma das primeiras manifestações da experimentação biopolítica:

De fato, a condição de escravo resulta de uma tripla perda: perda de um "lar", perda de direitos sobre seu corpo e perda de estatuto político. Essa tripla perda equivale a uma dominação absoluta, uma alienação de nascença e uma morte social (que é a expulsão fora da humanidade). Enquanto estrutura políticojurídica, a plantation é sem dúvida um espaço em que o escravo pertence ao senhor. (MBEMBE, 2018, p. 27)

Portanto, propomos que o ato de narrar empreendido por Conceição Evaristo transpõe para a literatura o papel do intelectual pós-colonial ao tratar as injustiças históricas relativas a genocídios, tortura, desterritorialização e outros crimes que renovam a discussão sobre os legados deixados pela escravidão, algo evidenciado também por Spivak em Pode o subalterno falar?, qual seja, como criar espaços para que o sujeito subalterno possa falar e, para que quando este o fizer, possa ser ouvido. Ainda nesse aspecto, Spivak (2010), ao reafirmar os estudos postulados por Derrida, defende que a desconstrução leva a uma prática adequada, seja na questão crítica, seja na política, buscando evitar que o sujeito etnocêntrico constitua um Outro a partir de si mesmo. Assim, a tarefa de recuperar a constituição do sujeito subalterno é ainda mais urgente em relação à questão da mulher,

Pode o subalterno falar? O que a elite deve fazer para estar atenta à construção contínua do subalterno? A questão da "mulher" parece ser a mais problemática 
nesse contexto. Evidentemente, se você é pobre, negra e mulher, está envolvida de três maneiras. (SPIVAK, 2010, p. 110)

Nesse contexto em que a mulher aparece duplamente obliterada, a escrita de Conceição Evaristo dá voz aos personagens subalternos ao trabalhar tanto o aspecto da memória coletiva quanto da memória individual, e o lugar de enunciação mostra-se solidário e em consonância com os marginalizados, sobretudo ao destacar a figura da mulher negra, que longe dos padrões estereotipados e perpetuados pelo discurso patriarcal como a "mulata fogosa e sensual", "mãe preta", "empregada doméstica", é materializada na escrita por meio de personagens femininas repletas de humanidade, força e subjetividade. Assim, por meio de narrativas que têm as mulheres como protagonistas, a autora legitima a história de outras mulheres. Esses traços, bem como os ecos das representações mnemônicas, serão analisados a partir da obra Ponciá Vicêncio (2003).

Tal romance caracteriza-se por uma narrativa circular, que entrecruza passado e presente, no qual a protagonista Ponciá evidencia uma trajetória que vai sendo organizada em torno da questão da memória. Em um processo de lembrar, a personagem explora a fundo a herança do passado relacionado à escravidão mediante a figura do avô, a morte do pai, o aborto dos filhos e o afastamento da família, bem como no processo de construção da sua própria identidade por meio das lembranças de sua infância e juventude, enfatizando a marginalidade e o abandono em que se encontra, pois, a sua herança escrava vai se confirmando na vida difícil que leva.

Enquanto traça a relação passado e presente e os diálogos recorrentes à memória, as personagens de Conceição Evaristo nos arrastam consigo no processo de lembrar, ao mesmo tempo que buscam denunciar as injustiças relacionadas ao passado escravista, que por centenas de anos criou um regime social que fomentou a desigualdade racial no país. Em Narrar ou descrever? Lukács (1936, p. 95) menciona que o "papel do grande escritor é não apenas descrever superficialmente aspectos da realidade, mas desenvolver uma relação íntima entre os acontecimentos da superfície e a necessidade social, e conceber uma escrita que seja a síntese dessa relação", decerto, o ato de narrar empreendido por Conceição imprime as marcas do passado e dialoga com o presente, atendendo aos debates em relação ao racismo, que o momento atual exige e propicia. 


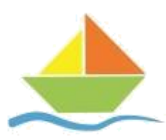

Nesse caso, a rememoração no romance Ponciá Vicêncio (2003) ocorre não apenas no plano individual da protagonista, como também alcança os demais personagens: seu pai, seu irmão Luandi, sua mãe e até mesmo as experiências da velha Nêngua Kainda, a anciã que vivia junto aos negros. As lembranças da protagonista selecionam, organizam e sistematizam acontecimentos que transitam entre a memória individual e a memória coletiva, conectando passado e presente e enfatizando certas facetas do mundo interior das personagens:

Ponciá Vicêncio gostava de ficar sentada perto da janela olhando o nada. [...] Ela gastava todo o tempo com o pensar, com o recordar. Relembrava a vida passada, pensava no presente, mas não sonhava nem inventava nada para o futuro. O amanhã de Ponciá era feito de esquecimento. Em tempos outros, havia sonhado tanto! Quando mais nova, sonhara até um outro nome para si. Não gostava daquele que lhe deram. (EVARISTO, 2003, p. 19)

A voz narrativa apresenta uma narradora em terceira pessoa, que observa não somente a protagonista como as demais personagens em uma tentativa diligente de reconstruir-se em seus aspectos identitários, sociais e históricos. Assim, para Pollak (1992) a memória é um elemento constituinte do sentimento de identidade, tanto individual como coletiva, na medida em que ela é também um fator extremamente importante do sentimento de continuidade e coerência de uma pessoa ou de um grupo em sua reconstrução de si.

Ora, é por meio das lembranças que as personagens vão recuperando a sua constituição como ser e o seu sentimento de pertencimento ao grupo, tal como ocorre com o personagem Luandi, irmão de Ponciá, que, ao visitar a exposição de trabalhos de barros, reconhece os objetos produzidos pela mãe e irmã:

Luandi, à medida que contemplava os objetos de seu passado presente, a vida da roça aflorava em suas lembranças. Viu a mãe e a irmã criando utilidades e enfeites a partir da massa da terra. (EVARISTO, 2003, p. 103 grifo nosso)

Em consonância a este aspecto, para Le Goff (1990) a memória configura-se como propriedade de conservar certas informações, a partir de um conjunto de funções psíquicas, por meio do qual o homem pode atualizar impressões ou informações passadas, ou que, por sua 
vez, este tem como passadas. Destarte, Pollak (1992) assevera que mesmo na forma individual, o trabalho da memória é inseparável da organização social da vida.

Nessa ótica, Assmann (2011) evidencia que a reformulação da identidade significa simultaneamente a reorganização da memória, por isso a necessidade desses personagens em transmitir suas memórias individuais, que acabam se entrelaçando como uma rede de lembranças, e que assume no decorrer da narrativa os liames das experiências e reflexões em torno da história familiar, dos traumas relacionados ao passado e injustiças decorrentes da escravidão, das angústias e dos anseios do presente sobre a condição social. É a memória que unifica a personagem Ponciá com os seus e que vai delineando cada indivíduo que compõem a geração Vicêncio:

Ponciá Vicêncio se lembrava pouco do pai. [...] Filho de ex-escravos, crescera na fazenda levando a mesma vida dos pais. Era pajem do sinhô-moço. Tinha a obrigação de brincar com ele. Era o cavalo onde o mocinho galopava sonhando conhecer todas as terras do pai. Tinham a mesma idade. Um dia o coronelzinho exigiu que ele abrisse a boca, pois queria mijar dentro. $\mathrm{O}$ pajem abriu. A urina do outro caía escorrendo quente por sua goela e pelo canto de sua boca. Sinhô-moço ria, ria. Ele chorava e não sabia o que mais lhe salgava a boca, se o gosto da urina ou se o sabor de suas lágrimas. (EVARISTO, 2003, p. 17)

Dessa maneira, ao adentrar nos meandros do íntimo da protagonista, o leitor também mergulha no passado histórico de seus antepassados, ou seja, as histórias familiares da personagem estão relacionadas diretamente às lembranças individuais, mesmo que a protagonista não tenha vivido diretamente o acontecimento. Para Pollak (1992), essa rememoração constante que Ponciá realiza durante toda sequência narrativa, constitui a chamada "memória herdada", que é a projeção ou identificação a um passado que se figura no imaginário de maneira profunda.

Tais evidências, seguem os estudos do teórico Maurice Halbwachs, que concebe a memória individual interligada à memória coletiva. Dessa forma, a memória para Halbwachs (1990) implica na composição do ser social do indivíduo, tal como a memória individual é resultado das inúmeras confluências e relações do pensamento coletivo; logo, esse estudioso relaciona a memória à atuação em um grupo social (real ou imaginário), na chamada 
comunidade afetiva, de maneira que, quando há o processo de lembrar, desloca-se de um grupo ao outro em pensamento. $\mathrm{O}$ grupo torna estáveis as lembranças. Tal aspecto é explorado a fundo no romance, pois, essas sucessivas lembranças são como o fio condutor que direciona os acontecimentos, como também, possibilita a continuidade dos capítulos, cada lembrança situa o personagem em determinado tempo, entrecortando passado, presente e futuro, assim como evidencia as desigualdades sociais, que se traduzem em violências de todo o tipo, desde a marginalização da figura de Luandi, irmão de Ponciá, tanto em relação ao trabalho, quanto no que tange o domínio das letras, passando ainda a violência doméstica sofrida pela protagonista Ponciá e o seu cotidiano de pobreza e exclusão.

Nessa ótica, a concepção de escrita da narradora, ao criar a personagem Ponciá, utiliza a memória como um recurso combativo que evidencia a violência e o trauma acometidos contra o seu grupo social, apresentando uma estruturação memorialística que vincula sua criação estética a elementos históricos,

O tempo passava e ali estavam os antigos escravos, agora libertos pela "Lei Áurea", os seus filhos, nascidos do "Ventre livre" e os seus netos, que nunca seriam escravos. Sonhando todos sob os efeitos de uma liberdade assinada por uma princesa, fada-madrinha, que do antigo chicote fez uma varinha de condão. Todos, ainda, sob o jugo de um poder que, como Deus, se fazia eterno. (EVARISTO, 2003, p.48-49)

Na visão de Paul Ricoer (2010), a ficção se põe a serviço do inesquecível, ao fundir-se com acontecimentos históricos que foram marcantes em barbárie para um determinado grupo, pois, a ficção consegue por meio da voz narrativa, "retratar" "colocar diante dos olhos". É notório, a partir da leitura dos fragmentos expostos sobre o romance, que a obra de Conceição Evaristo perpassa as injustiças decorrentes do sistema escravocrata, como também, mantém-se atenta para a ressignificação da identidade negra, de maneira insurgente, como aponta a reflexão proposta por Luandi no último capítulo do livro:

A irmã tinha os traços e os modos de Vô Vicêncio. Não estranhou a semelhança que se fazia cada vez maior. Bom que ela fizesse reveladora, se fizesse herdeira de uma história tão sofrida, porque enquanto o sofrimento estivesse vivo na memória de todos, quem sabe não procurariam, nem que 


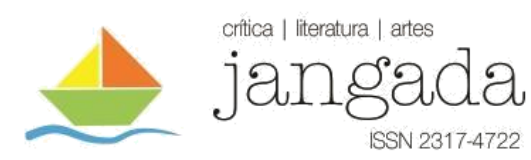

fosse pela força do desejo, a criação de um outro destino. (EVARISTO, 2003, p. 126)

Desse modo, a abordagem do romance afro-brasileiro Ponciá Vicêncio (2003) compõe um mosaico de lembranças que possibilita analisar os sujeitos ficcionais, bem como a narrativa a partir do viés memorialístico, em que a memória individual e a coletiva se fundem na intenção de desestabilizar as máscaras que historicamente silenciaram anos de opressão e obliteração do sujeito negro, como também evidenciar o compromisso com o caráter identitário, documental e coletivo, por meio de uma narrativa cortante e poética, que busca reconstruir a história dos seus "Dos que foram, dos que estavam sendo e dos que viriam a ser." (EVARISTO, 2003, p. 127).

Assim, com o mesmo intuito que Primo Levi afirma em Os afogados e os sobreviventes, "por uma espécie de obrigação moral para com os emudecidos ou, então, para nos livrarmos de sua memória: com certeza o fazemos por um impulso forte e duradouro”, Conceição Evaristo, por meio da protagonista Ponciá Vicêncio, explora os labirintos e as vias tortuosas da memória, à medida que, denuncia e desmistifica um universo inteiro de exclusão.

\section{A POÉTICA DO SILÊNCIO E O TRAUMA EM PONCIÁ VIVÊECIO}

Em seus estudos sobre a estética do silêncio, Susan Sontag defende que a arte do nosso tempo é ruidosa e com apelos ao silêncio, e que o "silêncio" nunca deixa de implicar seu oposto e depender de sua presença: é necessário reconhecer um meio circundante de som e linguagem para se admitir o silêncio. (SONTAG, 1987, p. 18). Em um espaço pleno da narrativa que é o texto, cultivar o silêncio surge como uma estratégia do narrador, para expressar poeticamente aquilo que a linguagem não alcança dizer:

Quando nada, porque a obra de arte existe em um mundo preenchido com muitas outras coisas, o artista que cria o silêncio ou vazio deve produzir algo dialético: um vácuo pleno, um vazio enriquecedor, um silêncio ressoante ou eloquente. O silêncio continua a ser, de modo inelutável, uma forma de discurso (em muitos exemplos, de protesto ou acusação) e um elemento em um diálogo. (SONTAG, 1987, p.18) 


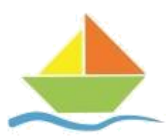

O silêncio aparece como um aspecto dialético da linguagem no romance Ponciá Vicêncio, pois tal elemento permite ao leitor adentrar no universo interior da memória da protagonista, assim como compartilhar de suas perdas, ausências e angústias. Tal aspecto nos remete às profundas buscas que os personagens fazem de si mesmo, bem como compreendê-lo como uma espécie de transgressão a uma condição marcada pelas diferenças sociais, econômicas e raciais.

Assim, do ponto de vista formal, o texto é marcado pelo emaranhado de lembranças, quase sempre entrecortado pelo silêncio angustiante da personagem Ponciá, algo que para Steiner (1988, p.74) "é uma seleção que possibilita reinscrever outro sentido para o romance, pois [...] se as palavras estão impregnadas de selvageria e mentiras, nada fala mais alto do que o poema não escrito".

Nesse sentido, o recurso do silêncio configura-se como uma metáfora gradual da condição subalterna da protagonista, pois à medida que Ponciá tece as suas reminiscências, compartilha os vestígios traumáticos dessa memória e assim vai acentuando a configuração de sua mudez, que se manifesta de modo mais agudo no decorrer da trama. Cada busca por um lugar que simbolize esperança é interrompida por perdas e marcas da violência:

As ausências, além de mais constantes, deixavam Ponciá durante muito tempo fora de si. [...] Quando viu Ponciá parada, alheia, morta-viva, longe de tudo, precisou fazê-la doer também e começou a agredi-la. Batia-lhe, chutava-a, puxava-lhe os cabelos. Ela não tinha um gesto de defesa. Quando o homem viu o sangue a escorrer-lhe pela boca e pelas narinas, pensou em matá-la, mas caiu em si assustado. [...] Ela não reagia, não manifestava qualquer sentimento de dor ou de raiva. E desde esse dia, que o homem lhe batera violentamente, ela se tornou quase muda. (EVARISTO, 2003, p. 96)

É a narradora que "fala" por ela, evidenciando mais um aspecto importante do silenciamento da personagem, pois, desde o princípio é a voz narrativa que conta a sua infância, juventude e fase adulta, na qual o silêncio da protagonista e sua "quase mudez" metaforizam as instituições de poder e violência em que, segundo Assmann (2011), a relação entre dor e memória configura-se pela ideia de que a memória corporal se fixa, mesmo após o alívio dessa dor, em traços e cicatrizes. 


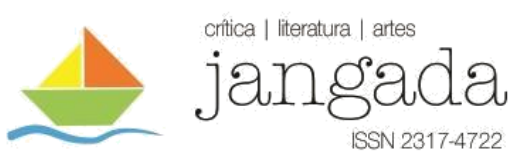

Por isso, no decorrer do texto literário, os termos "nada", "vazio", "buraco", "fenda" e "vácuo" são repetidos enfaticamente inúmeras vezes, operando como metáforas que refletem o estado de alheamento da personagem Ponciá diante da opressão e violência à qual estava submetida. Seu comportamento centrado na ausência de si mesma expressava as palavras que sua boca não proferia, porém, seu corpo parecia emergir através dos seus desmaios, apatia e vazio profundo. Seu sofrimento é tamanho que podemos ouvir o ecoar do grito emudecido e agonizante da protagonista.

Em face dessas experiências traumáticas vividas por Ponciá, que acentuam a evidência do silêncio, os demais acontecimentos acometidos contra o seu grupo social, corporificam a reprodução real da violência:

Rememorando as lágrimas-risos do avô, Ponciá se recordou de uma história contada por seu irmão, depois que o pai havia morrido. [...] Os engenhos de açúcar enriqueciam e fortaleciam o senhor. Sangue e garapa podiam ser um líquido só. Vô Vicêncio com a mulher e os filhos viviam anos e anos nessa lida. Três ou quatro dos seus, nascidos do "ventre livre", entretanto, como muitos outros, tinham sido vendidos. Numa noite, o desespero venceu. Vô Vicêncio matou a mulher e tentou acabar com a própria vida. Armado com a própria foice que lançara contra a mulher, começou a se flagelar decepando a mão. (EVARISTO, 2003, p.51)

No dia em que Ponciá Vicêncio desceu do colo da mãe e começou a andar, causou uma grande surpresa. [...] Veio forçando a descida pelo colo da mãe e pondo-se de pé, começou as andanças. Surpresa maior não foi pelo fato de a menina ter andado tão repentinamente, mas pelo modo. Andava com um dos braços escondido às costas e tinha a mãozinha fechada como se fosse cotó. (EVARISTO, 2003, p. 16)

Nessa ótica, Pollak (1992) expressa que podem existir acontecimentos regionais que traumatizaram tanto uma região ou um grupo, que sua memória pode ser transmitida ao longo dos séculos com altíssimo grau de identificação, assim, mesmo que a protagonista não tenha passado pelo episódio encenado por vô Vicêncio, tem consciência da circunstância que o trauma gerou em toda a sua existência, por isso, a analogia ao "braço cotó" que fazia quando criança. 
Os silêncios, os vazios e os alheamentos tão personificados na protagonista do romance Ponciá Vicêncio são estratégias literárias empreendidas por Conceição Evaristo como um recurso combativo que visa, por meio da escrita memorialística, denunciar as experiências traumáticas e toda a barbárie empreendida pelos séculos de escravidão, bem como traçar um paralelo sobre a condição social e marginalizada que grande parte da população afrodescendente ainda vive, tais como a violência urbana, o racismo e as mazelas dos espaços periféricos que ainda se impõem ao povo negro.

O silêncio de Ponciá simboliza o silêncio em relação aos escritores das margens, aos modelos estruturantes por meio de ideologias elitistas, as mulheres negras e periféricas que sofrem violência diariamente, os negros que ainda compõem dois terços do sistema carcerário brasileiro e o silêncio enlutado diante dos alarmantes $71 \%$ de negros perfazendo a maioria das vítimas de homicídio, portanto, as tessituras de Conceição Evaristo são importante para desconstruir padrões cristalizados por parâmetros opressores, que visam a questionar diretamente a dura e desigual realidade à qual estão submetidos o negro e sua perspectiva social.

\section{CONSIDERAÇÕES FINAIS}

As tessituras memorialísticas de Conceição Evaristo encenam por meio de uma escrita combativa e insurgente, os traumas oriundos das relações históricas perpetrados pelo sistema de escravidão e os seus alcances em nossos dias. Ligando essas redes da memória, quer seja de um lado pela herança de Vô Vicêncio marcada pela perda e precariedade, ora do riso, ora do choro "assistiu, chorando e rindo, aos sofrimentos, aos tormentos de todos. E só quando acabou de rir todos os seus loucos risos e de chorar os seus insanos prantos, foi que Vô Vicêncio se quedou calmo" (EVARISTO, 2003, p. 52), qual seja, pelo silêncio transgressor e resistente de Ponciá “[...] a voz de mando, a terra dos brancos, a resistência teimosa e muitas vezes silenciosa do negro, travestida de uma falsa obediência ao branco. [...]" (Idem), a literatura encena e atualiza essa ligação entre o passado colonial e os rastros dessa herança que se mantém em nossos dias repletos de não-lugares ocupados pelos negros em nossa sociedade.

Nesse sentido, tal forma de narrar parte do princípio estabelecido por Benjamin (1986) em $O$ narrador, em que a escrita surge como experiência individual, um lastro próprio do indivíduo que existe como forma de manter viva a memória de seu clã, para que tais lembranças não se percam, “é ela própria, num certo sentido, uma forma artesanal de comunicação. Ela não 


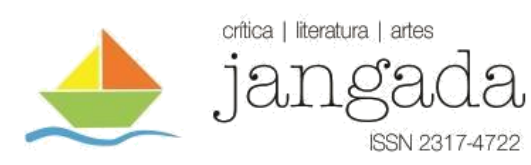

está interessada no 'puro em si' da coisa narrada como uma informação ou relatório. Ela mergulha a coisa na vida do narrador para em seguida retirá-la dele.” (BENJAMIN, 1986, p. 205). É um ato de transformação tanto individual como coletiva, assim o romance Ponciá Vicêncio encena uma forma de contar que capta o leitor para o drama das populações negras.

No mais, as histórias contadas por Conceição Evaristo exploram uma narratividade que funciona do ponto de vista benjaminiano como "circulatório de sabedoria", tendo em vista que, ao encenar as experiências traumáticas, a ficção funciona como práxis, uma vez que o texto é tido como elemento de transformação social, "tudo isso esclarece a natureza verdadeira da narrativa. Ela tem sempre em si, às vezes de forma latente, uma dimensão utilitária." (BENJAMIN, 1986, p. 200). Tal dimensão utilitária possibilita a literatura corporificar os dilemas vivenciados pelos indivíduos marginalizados.

As produções evaristianas, portanto, funcionam como um repositório de memórias tanto individuais, quanto coletivas, pois, encenam novas formas de contar as experiências e os traumas, interessantes e propícios, pois desconstroem os discursos condensados na tradição literária, que legitimam a violência e a marginalidade constituindo-se em uma estratégia de denúncia contra toda e qualquer opressão resultante das relações raciais.

\section{REFERÊNCIAS BIBLIOGRÁFICAS}

ADORNO, Theodor W. Dialética negativa. Rio de Janeiro: J. Zahar, 2009. 1986.

. Educação após Auschwitz. In: ADORNO, Theodor W. Sociologia. São Paulo: Ática,

ASSMANN, Aleida. Espaços da recordação: formas e transformações da memória cultural. Tradução Paulo Soethe. Campinas, SP: Editora da Unicamp, 2011.

BENJAMIN, Walter. O narrador. In: BENJAMIN, Walter. Magia e Técnica, Arte e Política: ensaios sobre a literatura e história da cultura. Trad. Sérgio Paulo Rouanet, $2^{\circ}$ ed., Brasiliense, 1986.

EVARISTO, Conceição. Da grafia desenho de minha mãe, um dos lugares de nascimento da minha escrita. Mesas de Escritoras Afro-brasileiras. IX SEMINÁRIO NACIONAL MULHER E LITERATURA/ II SEMINÁRIO INTERNACIONAL MULHER E LITERATURA, Rio de Janeiro, 2005. Disponível em: < http://nossaescrevivencia.blogspot.com/2012/08/da-grafiadesenho-de-minha-mae-um-dos.html>. Acesso em: 01 junho 2019.

. Ponciá Vicêncio. Belo Horizonte: Mazza, 2003.

HUYSSEN, Andreas. Seduzidos pela memória: arquitetura, monumentos, mídia. Rio de Janeiro: Aeroplano, 2000.

Jangada | nr. 14, jul/dez, 2019 | ISSN 2317-4722

18 | Pá g in a 


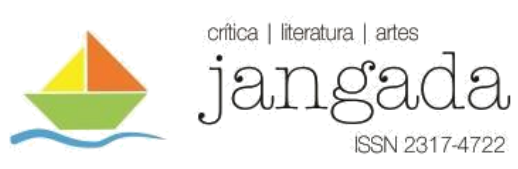

HALBWACHS, Maurice. A memória coletiva. Tradução de Laurent Léon Schaffter. São Paulo: Editora Revista dos Tribunais LTDA, 1990.

SELIGMANN-SILVA, Márcio. 2001. Literatura e Trauma: um novo paradigma. In: Rivista di Studi Portoghesi e Brasiliani III (2001), Pisa e Roma, pp. 103-118. In: O local a diferença. Ensaios sobre memória, arte, literatura e tradução, São Paulo: Editora 34, 2005, pp. 63-80.

História, Literatura e Memória. O testemunho na era das catástrofes. Campinas:

Editora da Unicamp, 2003.

A atualidade de Walter Benjamin e de Theodor W. Adorno. Rio de Janeiro:

Civilização Brasileira, 2009.

SONTAG, Susan. A "estética do silêncio". In: A vontade radical: estilos. Tradução de João Roberto Martins filho. São Paulo: Companhia das Letras, 1987, p.11-40.

STEINER, George. Linguagem e silêncio. Ensaios sobre a crise da palavra. Tradução de Gilda Stuart e Felipe Rajabally. São Paulo: Companhia das Letras, 1988.

LE GOFF, Jacques. História e memória. Tradução Bernardo Leitão [et al.] -- Campinas, SP Editora da UNICAMP, 1990.LEVI, Primo. É isto um homem? Tradução de Luigi Del Re. Rio de Janeiro: Rocco, 1988.

LUKÀCS, George. Narrar ou descrever? In: Ensaios sobre Literatura. Tradução de Giseh Vianna Konder. $2^{\circ}$ ed, Editora Civilização brasileira, 1936.

RICOEUR, Paul. Tempo e narrativa. Tradução de Claudia Berliner. São Paulo: Editora WMF Martins Fontes, 2010.

SPIVAK, Gayatri. Pode o subalterno falar? Tradução de Sandra Regina Goulart. Belo Horizonte: Editora UFMG, 2010.

TAYLOR, Diana. O arquivo e o repertório: performance e memória cultural nas Américas. Tradução de Eliana Lourenço de Lima Reis. Belo Horizonte: Editora UFMG, 2013.

MBEMBE, Achille. Necropolítica: Biopoder, soberania, estado de exceção, política da morte. In: Arte \& Ensaios. Tradução de Renata Santini. $3^{\circ}$ ed, São Paulo, 2018.

POLLAK, Michael. Memória e identidade social. In: Estudos históricos. Vol.5, n.10, 1992, p. 200-212. 